\title{
Disparities in US Healthcare Provider Screening and Advice for Cessation Across Chronic Medical Conditions and Tobacco Products
}

\author{
Diana R. Keith, $P h D^{7}$, Cassandra A. Stanton, $P h D^{2,3}$, Diann E. Gaalema, $P h D^{7}$, Janice Y. Bunn, $P h D^{1,4}$, \\ Nathan J. Doogan, PhD", Ryan Redner, PhD ${ }^{7,6}$, Allison N. Kurti, PhD ${ }^{7}$, Antonio Cepeda-Benito, PhD”, \\ Alexa A. Lopez, PhD ${ }^{7}$, Adam L. Morehead, BA ${ }^{7}$, Megan E. Roberts, PhD ${ }^{5}$, and Stephen T. Higgins, \\ $P h D^{7}$
}

\begin{abstract}
${ }^{1}$ Vermont Center on Behavior and Health, Department of Psychiatry, University of Vermont, Burlington, VT, USA; ${ }^{2}$ Westat, Rockville, MD, USA; ${ }^{3}$ Department of Oncology, Georgetown University Medical Center/Cancer Prevention and Control Program, Washington, DC, USA; ${ }^{4}$ Department of Medical Biostatistics, University of Vermont, Burlington, VT, USA; ${ }^{5}$ College of Public Health, The Ohio State University, Columbus, OH, USA;

${ }^{6}$ Rehabilitation Institute, Southern Illinois University, Carbondale, IL, USA; ${ }^{7}$ Department of Psychological Science, University of Vermont, Burlington, VT, USA.
\end{abstract}

BACKGROUND: Disparities in tobacco use are worsening in the United States, disproportionately affecting those with chronic medical conditions. One possible contributor is that physicians may not screen and advise cessation uniformly across patients and/or tobacco products.

OBJECTIVE: This study examined provider communications regarding cigarette and non-cigarette tobacco products among adults with chronic conditions.

DESIGN: Cross-sectional study drawn from two waves (2013-2014) of the National Survey on Drug Use and Health (NSDUH).

PARTICIPANTS: Adults ( $\geq 18$ years) who used tobacco in the past year.

MAIN MEASURES: Prevalence of tobacco use included past-year use of cigarettes, cigars, or smokeless tobacco among those with and without chronic conditions. Chronic conditions included asthma, anxiety, coronary heart disease, depression, diabetes, hepatitis, HIV, hypertension, lung cancer, stroke, and substance abuse. Odds ratio of receipt of screening and advice to quit across chronic condition and tobacco product type were reported. Data were analyzed using logistic regression, controlling for basic sociodemographic factors and number of provider visits.

KEY RESULTS: Adults with anxiety, depression, and substance use disorders had the highest prevalence of past-year cigarette (37.2-58.2\%), cigar (9.1-28.0\%), and smokeless tobacco (3.1-11.7\%) use. Patients with any chronic condition were more likely to receive advice to quit than those without a condition (OR 1.21-2.37, $p<0.01$ ), although the odds were lowest among adults with mental health and substance use disorders (OR 1.21-1.35, $p<0.01)$. Cigarette smokers were more likely to report being screened and advised to quit than non-cigarette tobacco users (OR 1.54-5.71, $p<0.01$ ).

CONCLUSIONS: Results support the need for provider training to expand screening and cessation interventions to include the growing spectrum of tobacco products.

Received August 30, 2016

Revised February 8, 2017

Accepted March 31, 2017

Published online May 3, 2017
Screening and referral to interventions are especially needed for those with mental health and substance use disorders to reduce the disparate burden of tobaccorelated disease and death.

KEY WORDS: chronic conditions; tobacco use; comorbidity; physician advice; cigarettes; cigars; smokeless tobacco; health disparities. J Gen Intern Med 32(9):974-80 DOI: $10.1007 / \mathrm{s} 11606-017-4062-6$

(C) Society of General Internal Medicine 2017

\section{INTRODUCTION}

Various tobacco control and prevention policies have contributed to a significant decline in the prevalence of cigarette smoking in the United States over the past decade. ${ }^{1},{ }^{2}$ This decline is not uniform across the US population, as disparities in tobacco use have been reported by gender, sexual orientation, age, race, ethnicity, education level, insurance status, disability, and annual income. ${ }^{3-7}$ One recent report from a nationally representative survey (National Survey on Drug Use and Health, NSDUH) noted disparities in the prevalence of tobacco use among adults coping with chronic medical conditions. $^{8}$ While cigarette smoking declined significantly from 2005 to 2013 among adults without chronic conditions, smoking rates among adults with chronic conditions remained stable, with rates especially high among those with anxiety, depression, and substance use disorders. Use of non-cigarette tobacco products steadily increased among those with and without chronic conditions. ${ }^{8}$

Adults coping with chronic conditions are at increased risk of further harm if they continue to use tobacco, yet data suggest that physicians may not be screening for use and recommending cessation uniformly across tobacco products and patients. ${ }^{9}$ While national guidelines suggest that clinicians should ask about all tobacco use and advise effective brief treatments (i.e., the 5As: Ask, Advise, Assess, Assist, Arrange), ${ }^{10}$ national data sets indicate that only half of all 
smokers report receiving provider advice to quit. ${ }^{9}$ If those with chronic conditions are less likely to receive physician communications regarding tobacco use, this could contribute to perpetuating the current disparities in smoking rates between those with and without chronic conditions. Further, if patients with certain conditions (e.g., mental health and substance use disorders) are less likely to receive provider communications relative to patients with other conditions, disparities in tobacco use in the US may continue to widen.

Indeed, some evidence suggests that patients with certain conditions are more likely to receive provider advice and cessation resources. Physicians may be more likely to advise quitting to those who are sicker or who have diseases that are considered "smoking-related" (e.g., cardiac, respiratory, or cerebrovascular conditions). ${ }^{11-15}$ However, much of this literature is outdated, is focused exclusively on cigarette smoking, and does not examine how advice varies as a function of type of chronic condition and/or tobacco product. Physician behavior surrounding non-cigarette tobacco use is especially understudied. In the only study that we are aware of on this topic, less than one-fifth of snuff or chewing tobacco users reported receiving advice to quit from a healthcare provider, compared to over half of cigarette smokers. ${ }^{16}$ This gap in our knowledge is concerning, given the growing popularity and spectrum of non-cigarette tobacco products (e-cigarettes, dissolvable products, cigarillos, etc.).

This study expands on prior reports ${ }^{8}$ by examining patientreported healthcare provider screening and advice to quit tobacco use across tobacco products and chronic conditions.

\section{METHODS}

The National Survey of Drug Use and Health (NSDUH) was the source of the data used for this report. ${ }^{17},{ }^{18} \mathrm{NSDUH}$ is a survey of individuals 12 years of age and older, designed as a nationally representative survey of the civilian, noninstitutionalized United States population. This annual survey examines the use of alcohol, tobacco, and illicit drug use, as well as providing information on both mental health and medical conditions. Respondents were identified through a multi-stage sampling scheme, with allowances made for over-representation of youth and young adults. The use of such a design is reflected in the sampling weights that are provided as part of all public-use data sets. Items regarding healthcare providers' assessment of tobacco use and advice to quit tobacco use were added in 2013 and continued for the 2014 interviews, the most recent interview data available. Because of insufficient numbers of individuals with some of the chronic diseases of interest in a single year, this report is based on combined data from both years. In order to account for the use of 2 years of surveys, the sample weights provided were divided by 2 , as indicated in the NSDUH guidelines. The response rates were $71.7 \%$ for 2013 and $71.2 \%$ for 2014 , with an overall sample size of 135,739 . The current report is limited to the 77,645 respondents 18 years of age or older. Dependent variables were 1) self-reported past-year use of cigarettes, cigars, or smokeless tobacco, 2) self-reported receipt of provider screening for tobacco use ("During the past 12 months, did any doctor or other healthcare professional ask, either in person or on a form, if you used tobacco?") and 3) advice from a healthcare provider to quit using tobacco ("During the past 12 months, did any doctor or other healthcare professional advise you to quit smoking cigarettes or quit using any other tobacco products?"). Only those who reported using tobacco within the last 12 months were asked if their healthcare provider advised them to quit using tobacco.

Past-year smoking was assessed by asking respondents whether they had smoked all or part of a cigarette in the 1year period prior to the interview. Similarly, respondents were asked whether they had smoked all or part of a cigar in the past year and whether they used snuff or chewing tobacco in the past year, with the latter being combined to form a single variable assessing the use of smokeless tobacco. Because questions regarding pipe smoking asked only about use in the previous 30 days, respondents whose tobacco use was limited to pipes were eliminated from all analyses. In order to ensure comparability of the tobacco use definitions, past-year cigarette smoking was defined as any reported use of cigarettes in the past year; lifetime cigarette use was not considered in this definition because it was not assessed for the other forms of tobacco use. No attempt was made to assess the impact of the use of multiple forms of tobacco for the assessment of past-year prevalence of tobacco use. For examination of healthcare providers' assessment of tobacco use and advice to quit, respondents who endorsed using cigarettes as well as other forms of tobacco were considered cigarette smokers, while those who endorsed using cigars and/or smokeless tobacco, but not cigarettes, were categorized as using non-cigarette tobacco products. NSDUH does not ask about the use of electronic cigarettes.

The definition of chronic condition was based on a set of 20 conditions cited by the US Department of Health and Human Services. ${ }^{19}$ Not all chronic conditions were assessed as part of NSDUH; therefore, the list of chronic conditions was limited to hypertension, coronary heart disease, hepatitis, stroke, diabetes, asthma, lung cancer, human immunodeficiency virus (HIV) infection, depression, anxiety, and substance abuse With the exception of substance abuse, the respondents were asked "Which, if any, of these conditions did a doctor or medical professional tell you that you had in the past 12 months?" Substance abuse was determined based on responses to questions regarding alcohol and drug use according to an algorithm developed by NSDUH investigators in accordance with the abuse and dependence criteria in the Diagnostic and Statistical Manual of Mental Disorders, Fourth Edition (DSM-IV), and was used as recoded in the publicuse data set. ${ }^{20}$ 


\section{Statistical Analyses}

Prevalence of past-year tobacco use was examined among all respondents age 18 years and older, adjusting only for sampling weights. Relationships between healthcare provider screening of tobacco use, advice to quit tobacco use, product type, and chronic condition were examined using multiple logistic regression, controlling for age, race, gender, education, age at first use, and number of provider visits in the past year. These analyses were limited to respondents selfidentifying as past-year tobacco users. Analyses examined the effect of having at least one chronic condition and each of seven separate conditions, provided there was at least one person with that condition in each of the sampling strata. Because there were fewer than 20 respondents reporting having been told they had been diagnosed with hepatitis, HIV, lung cancer, or stroke, these conditions are not examined separately. All analyses were conducted using the weighted survey logistic procedure in STATA version 13 software.1. Odds ratios and $95 \%$ confidence intervals (CIs) are reported, with statistical significance set to $p<0.05$.

\section{RESULTS}

Table 1 displays the latest past-year tobacco prevalence rates across cigarette and non-cigarette tobacco products for adults with and without chronic conditions. Across 2013-2014, an average of $32.5 \%$ reported using cigarettes, cigars, or smokeless tobacco in the previous year, with cigarettes the most frequently used product $(26.5 \%)$. Adults with anxiety, depression, and substance use disorders had the highest past-year use of cigarettes $(42.2,37.3$, and $58.0 \%$, respectively) and cigars $(11.5,9.9$, and $26.8 \%$, respectively), and some of the highest rates of smokeless tobacco use $(4.1,3.2$, and $11.6 \%$, respectively).

Most respondents $(84.9 \%, n=16,719)$ reported that their provider screened for tobacco use, but rates varied by chronic condition and tobacco product (Table 2). Tobacco users diagnosed with at least one of the chronic conditions in the past year were more likely to have been screened for tobacco use than those without a chronic condition (Table 4; AOR [95\% $\mathrm{CI}]=1.21[1.07,1.38], p<0.01)$. When examined by type of chronic condition, only adults with diabetes $(92.7 \%$; AOR $[95 \% \mathrm{CI}]=1.82[1.29,2.58], p<0.01)$ and hypertension (90.7\%; AOR [95\% CI] $=1.51[1.20,1.90], p<0.01)$ were more likely to be asked about tobacco use when compared to those without a chronic condition (82.3\%). However, regardless of condition, cigarette smokers were more likely to report being screened for tobacco use than non-cigarette tobacco users $(\mathrm{AOR}[95 \% \mathrm{CI}]=1.54[1.34,1.77], p<0.01)$.

Self-reported receipt of advice to quit also varied by both chronic condition and tobacco product (Table 3). Tobacco users with at least one of the conditions of interest were more likely to have received provider advice to quit than those without a chronic condition (Table 4; AOR [95\%

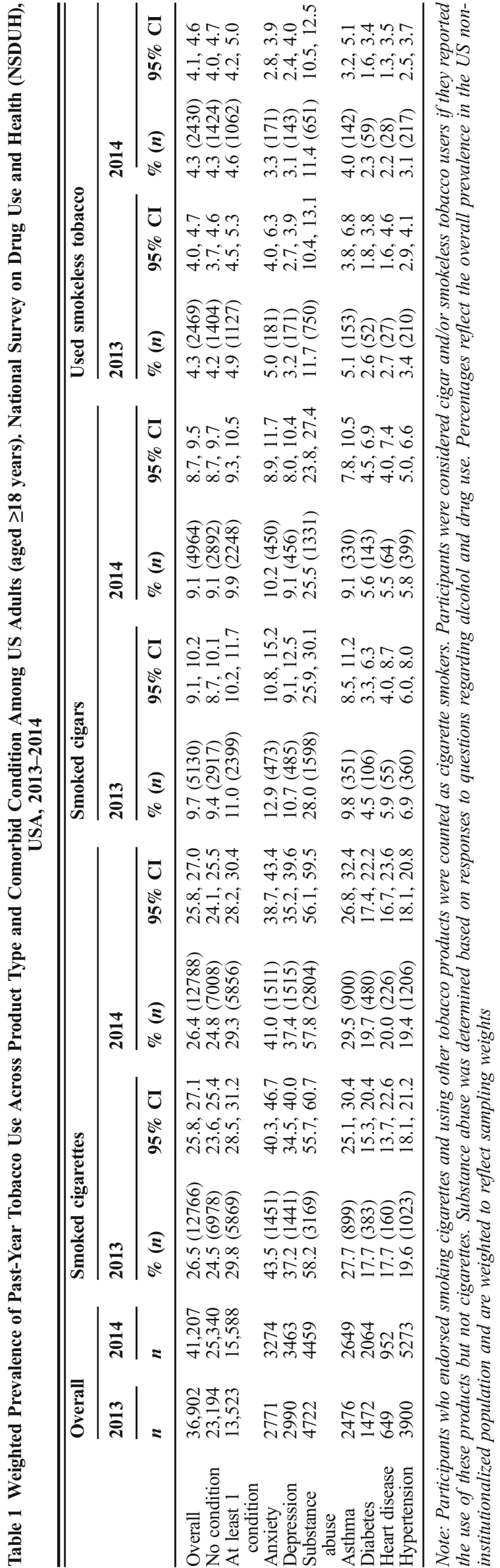


Table 2 Prevalence of Respondents' Self-Report of Past-Year Screening for Tobacco Use Across Chronic Health Conditions and Tobacco Product Type Among US Adults (aged $\geq 18$ years). National Survey on Drug Use and Health (NSDUH), USA, 2013-2014

\begin{tabular}{|c|c|c|c|c|}
\hline & \multicolumn{4}{|c|}{ Asked about use } \\
\hline & \multicolumn{2}{|c|}{ Smoked cigarettes } & \multicolumn{2}{|c|}{$\begin{array}{l}\text { Used non-cigarette } \\
\text { tobacco products }\end{array}$} \\
\hline & $\begin{array}{l}\text { Weighted } \\
\%\end{array}$ & $\begin{array}{l}\text { (Asked } \\
\text { about } \\
\text { use, } n \text { ) }\end{array}$ & $\begin{array}{l}\text { Weighted } \\
\%\end{array}$ & $\begin{array}{l}\text { (Asked } \\
\text { about } \\
\text { use, } n \text { ) }\end{array}$ \\
\hline No condition & 82.3 & (8068) & 77.8 & (1896) \\
\hline $\begin{array}{l}\text { At least } 1 \\
\text { condition }\end{array}$ & 87.3 & (8651) & 77.9 & (1273) \\
\hline Anxiety & 90.0 & (2487) & 88.6 & (212) \\
\hline Depression & 90.6 & (2495) & 79.6 & (201) \\
\hline $\begin{array}{l}\text { Substance } \\
\text { Abuse }\end{array}$ & 83.2 & (3890) & 79.4 & $(513)$ \\
\hline Asthma & 87.5 & (1380) & 70.4 & $(206)$ \\
\hline Diabetes & 92.7 & $(762)$ & 78.6 & (122) \\
\hline Heart disease & 94.0 & (343) & 67.5 & (59) \\
\hline Hypertension & 90.7 & (1889) & 78.8 & (418) \\
\hline
\end{tabular}

Note: Participants who endorsed smoking cigarettes and using other tobacco products were counted as cigarette smokers. Participants were considered cigar and/or smokeless tobacco users if they reported the use of these products but not cigarettes. Substance abuse was determined based on responses to questions regarding alcohol and drug use. Percentages reflect the overall prevalence in the US noninstitutionalized population and are weighted to reflect sampling weights

$\mathrm{CI}]=1.35[1.25,1.47], p<0.01)$. This was independent of type of condition (highest $p$-value, $p<0.01$ ). Similar to the results observed in screening for use, cigarette smokers were more likely to report being advised to quit when compared to non-cigarette tobacco users, regardless of

Table 3 Prevalence of Respondents' Self-Report of Past-Year Advice to Quit Tobacco Use Across Chronic Health Conditions and

Tobacco Product Type Among US Adults (aged $\geq 18$ years). National Survey on Drug Use and Health (NSDUH), USA, 2013-2014

\begin{tabular}{|c|c|c|c|c|}
\hline & \multicolumn{4}{|c|}{ Advised to quit } \\
\hline & \multicolumn{2}{|c|}{ Smoked cigarettes } & \multicolumn{2}{|c|}{$\begin{array}{l}\text { Used non-cigarette } \\
\text { tobacco products }\end{array}$} \\
\hline & $\begin{array}{l}\text { Weighted } \\
\%\end{array}$ & $\begin{array}{l}\text { (Advised } \\
\text { to quit, } n \text { ) }\end{array}$ & $\begin{array}{l}\text { Weighted } \\
\%\end{array}$ & $\begin{array}{l}\text { (Advised } \\
\text { to quit, } n \text { ) }\end{array}$ \\
\hline No condition & 54.2 & (4794) & 17.8 & $(425)$ \\
\hline $\begin{array}{l}\text { At least } 1 \\
\text { condition }\end{array}$ & 66.0 & (6019) & 25.4 & (379) \\
\hline Anxiety & 67.4 & (1766) & 24.7 & (53) \\
\hline Depression & 69.5 & (1766) & 23.3 & (52) \\
\hline $\begin{array}{l}\text { Substance } \\
\text { Abuse }\end{array}$ & 56.3 & $(2465)$ & 20.9 & (135) \\
\hline Asthma & 69.4 & (1016) & 20.6 & $(56)$ \\
\hline Diabetes & 78.6 & (629) & 33.3 & (48) \\
\hline Heart Disease & 85.0 & (305) & 42.6 & (35) \\
\hline Hypertension & 75.9 & (1539) & 28.7 & (153) \\
\hline
\end{tabular}

Note: Participants who endorsed smoking cigarettes and using other tobacco products were counted as cigarette smokers. Participants were considered cigar and/or smokeless tobacco users if they reported the use of these products but not cigarettes. Substance abuse was determined based on responses to questions regarding alcohol and drug use. Percentages reflect the overall prevalence in the US noninstitutionalized population and are weighted to reflect sampling weights chronic condition $(\mathrm{AOR}[95 \% \mathrm{CI}]=5.71[4.92,6.64]$, $p<0.01$ ).

Although the proportion of individuals using at least two products was too low to conduct a separate analysis by chronic condition, multiple-product users made up $7.36 \%$ of the sample $(N=8733)$, with $26.05 \%(N=8277)$ of cigarette smokers reporting the use of at least one other product.

\section{DISCUSSION}

To our knowledge, this is the first study to use nationally representative data to assess provider communications about tobacco use across tobacco products and among adults with chronic conditions. Independent of chronic condition, the majority of respondents reported being screened for cigarette smoking (82.3-94.0\%) and advised to quit smoking cigarettes (54.2-85.0\%). In contrast, non-cigarette tobacco users reported substantially lower rates of screening and advice to quit (67.5-88.6\% screened and $17.8-42.6 \%$ advised to quit).

These findings on provider advice to quit smoking are consistent with other studies examining provider advice to quit among smokers in the general population. ${ }^{9},{ }^{13},{ }^{21}$ Crosssectional data from the National Health Interview Survey, for example, indicates that the percentage of smokers who reported receiving cessation advice was $50.7-53.5 \%$ between 2000 and $2010,{ }^{21}$ compared to $54.2 \%$ in the current sample. Considered together, these data suggest few gains over time in preventative healthcare practices targeting cigarette smoking among smokers in the general population.

Among those with at least one medical condition, $87.3 \%$ reported being screened for cigarette smoking and $66.0 \%$ reported receiving advice to quit. This is generally consistent with recent data showing that $86.5 \%$ of cancer patients ${ }^{22}$ and $87.5 \%$ of patients with chronic obstructive pulmonary disease $(\mathrm{COPD})^{23}$ reported receipt of screening and advice to quit, although fewer respondents in the current survey reported receiving advice to quit. Future studies utilizing the NSDUH may wish to assess whether provider communication regarding tobacco use changes over time among those with and without chronic conditions.

While it is heartening that healthcare providers seem to be targeting cigarette smoking for screening and advice to quit, compliance with guidelines to address non-cigarette tobacco use is significantly lower (cigarette vs. non-cigarette user screening: AOR 1.54, $p<0.01$; advice to quit: AOR 5.71, $p<0.01$ ). While approximately $78 \%$ of non-cigarette tobacco users reported that they were asked about tobacco use, only $17.8-25.4 \%$ reported that they were advised to quit. These data are difficult to interpret, given the dearth of studies examining provider communication about non-cigarette tobacco products; further examination of this area is necessary. It is possible that the low prevalence of advice to quit for noncigarette tobacco users was due in part to healthcare providers screening only for cigarette smoking rather than tobacco use, 
Table 4 Logistic Regression Predicting Provider Screening of Use and Advice to Quit Across Chronic Health Conditions and Tobacco Product Type Among US Adults (aged $\geq 18$ years). National Survey on Drug Use and Health (NSDUH), USA, 2013-2014

\begin{tabular}{|c|c|c|c|c|c|c|}
\hline & \multicolumn{3}{|l|}{ Asked about use } & \multicolumn{3}{|l|}{ Advised to quit } \\
\hline & OR (95\% CI) & $n$ & $p$-value* & OR $(95 \%$ CI) & $n$ & $p$-value* \\
\hline At least 1 condition & & 23,488 & & & 23,428 & \\
\hline Condition vs. none & $1.21(1.07,1.38)$ & & $<0.01$ & $1.35(1.25,1.47)$ & & $<0.01$ \\
\hline Cigarette vs. non-cigarette & $1.54(1.35,1.77)$ & & $<0.01$ & $5.71(4.92,6.64)$ & & $<0.01$ \\
\hline Anxiety & & 15,093 & & & 15,046 & \\
\hline Condition vs. none & $1.25(0.99,1.58)$ & & 0.06 & $1.31(1.14,1.52)$ & & $<0.01$ \\
\hline Cigarette vs. non-cigarette & $1.30(1.11,1.53)$ & & 0.01 & $5.46(4.55,6.56)$ & & $<0.01$ \\
\hline Depression & & 15,063 & & & 15,019 & \\
\hline Condition vs. none & $1.21(0.94,1.56)$ & & 0.13 & $1.35(1.17,1.55)$ & & $<0.01$ \\
\hline Cigarette vs. non-cigarette & $1.37(1.15,1.64)$ & & $<0.01$ & $5.60(4.60,6.82)$ & & $<0.01$ \\
\hline Substance abuse & & 17,312 & & & 17,266 & \\
\hline Condition vs. none & $1.06(0.93,1.21)$ & & 0.37 & $1.21(1.11,1.33)$ & & $<0.01$ \\
\hline Cigarette vs. non-cigarette & $1.30(1.12,1.50)$ & & $<0.01$ & $5.32(4.48,6.32)$ & & $<0.01$ \\
\hline Asthma & & 13,960 & & & 13,915 & \\
\hline Condition vs. none & $1.11(0.84,1.46)$ & & 0.46 & $1.50(1.28,1.77)$ & & $<0.01$ \\
\hline Cigarette vs. non-cigarette & $1.38(1.17,1.63)$ & & $<0.01$ & $5.53(4.52,6.78)$ & & $<0.01$ \\
\hline Diabetes & & 13,097 & & & 13,053 & \\
\hline Condition vs. none & $1.82(1.29,2.58)$ & & $<0.01$ & $1.89(1.50,2.37)$ & & $<0.01$ \\
\hline Cigarette vs. non-cigarette & $1.44(1.22,1.70)$ & & $<0.01$ & $5.66(4.68,6.84)$ & & $<0.01$ \\
\hline Heart disease & & 12,572 & & & 12,530 & \\
\hline Condition vs. none & $1.34(0.87,2.06)$ & & 0.19 & $2.37(1.70,3.29)$ & & $<0.01$ \\
\hline Cigarette vs. non-cigarette & $1.45(1.22,1.72)$ & & $<0.01$ & $5.55(4.49,6.88)$ & & $<0.01$ \\
\hline Hypertension & & 14,662 & & & 14,618 & \\
\hline Condition vs. none & $1.51(1.20,1.90)$ & & $<0.01$ & $1.65(1.43,1.89)$ & & $<0.01$ \\
\hline Cigarette vs. non-cigarette & $1.49(1.26,1.76)$ & & $<0.01$ & $5.20(4.94,7.10)$ & & $<0.01$ \\
\hline
\end{tabular}

Note: Results of a multivariate logistic regression analysis controlling for age, race, gender, education, age at first use, and number of provider visits in the past year. Participants who endorsed smoking cigarettes and using other tobacco products were counted as cigarette smokers. Participants were considered cigar and/or smokeless tobacco users if they reported use of these products but not cigarettes. Substance abuse was determined based on responses to questions regarding alcohol and drug use

*Values in bold indicate statistical significance

preventing the identification of non-cigarette tobacco users. It is also possible that healthcare providers view non-cigarette tobacco products as less prevalent and/or less harmful than cigarettes, and therefore devote less time to screening and cessation efforts. As some non-cigarette tobacco users (e.g., cigar smokers) use tobacco less regularly and in lower quantities (e.g., single cigar) than cigarette smokers, these patients may not report their tobacco use. Alternatively, providers may feel less equipped to help non-cigarette tobacco users quit, as less is known about treating non-cigarette tobacco use than cigarette smoking. ${ }^{24}$ However, a focus on non-cigarette tobacco products may be increasingly important, given the expanding spectrum of various new tobacco and nicotinedelivery products on the market (e-cigarettes, dissolvable products, hookah, snus, cigarillos, etc.), especially among vulnerable groups such as young adults, ethnic minorities, and those with low socioeconomic status. ${ }^{25}$ Although the NSDUH does not include questions regarding electronic cigarettes, the similar nature of electronic cigarettes and other tobacco products may result in similar findings. One report noted that lifetime use of electronic cigarettes increased from $1.8 \%$ to $13.0 \%$ between 2010 and $2013 .{ }^{26}$ Since 2013, the prevalence of electronic cigarette use has continued to increase, particularly among youth and young adults. ${ }^{27}$ Future research may wish to assess how healthcare providers communicate with patients regarding the use of e-cigarettes and other emerging products. Existing studies suggest that even brief structured counseling may significantly reduce smokeless tobacco use. ${ }^{28}$

Finally, the current study replicates and extends an earlier report ${ }^{8}$ by showing that, while adults with substance use and mental health disorders have the highest rates of tobacco use, they do not report higher rates of being screened for tobacco use or advised to quit. Unlike those coping with diabetes and hypertension, adults suffering from mental health and substance abuse disorders were no more likely to be screened for tobacco use than those without a medical or psychiatric condition. It is possible that healthcare providers are more familiar with the risks of exacerbating diabetes and hypertension by continuing to smoke, and are less familiar with the finding that smoking is a leading cause of morbidity and mortality in those with substance use and mental health disorders. ${ }^{29}$ Further, of all the conditions examined in this study, adults with mental health and substance use disorders reported the lowest odds of being advised to quit (OR 1.21-1.35 vs. 1.50-2.37 for non-mental health-related conditions). As those who cope with mental health and substance use disorders have greater difficulty quitting and are at greater risk of mortality from smoking-related diseases, ${ }^{30-32}$ they should be highpriority targets for provider communication and cessation resources. Beyond asking about use and advising quitting, it is vitally important for healthcare providers to help these smokers understand their treatment options and arrange for follow-up (i.e., the remaining 5As: Assess, Assist, Arrange). 
As evidence-based treatments are just as effective in this group as in those without mental health disorders, ${ }^{33}$ physician training and healthcare incentives to ensure support for high-risk adults coping with mental health and substance use disorders are essential for reducing these disparities.

Several limitations merit mention. All measures were self-reported and may be subject to recall bias. Further, this report was limited to studying only the chronic conditions and tobacco products measured in the NSDUH surveys. To ensure compatibility of tobacco use definitions across products, thresholds for lifetime use were not used, which may have inflated estimates of prevalence. The absence of data on e-cigarettes and low sample sizes for multiple tobacco product use, hepatitis, HIV, lung cancer, and stroke prohibited separate examination in our analyses. Findings were also limited to 2013-2014, as questions regarding provider communication were not administered in earlier waves. Finally, NSDUH is a crosssectional survey that does not allow for causal inferences about the relationships between tobacco use and diagnosis of a chronic condition. All respondents were asked to report whether a physician had told them that they had a chronic condition in the past 12 months; therefore, it was not possible to ascertain the length of time since initial diagnosis. Future research using longitudinal methods (i.e., Population Assessment of Tobacco and Health, PATH) will be important in parsing how these variables unfold within an individual over time. Further, it will be important for future research to determine the influence of sociodemographic factors (i.e., age, gender, race, education) on the likelihood of receiving screening/advice to quit across tobacco products and among those with chronic conditions.

Despite these limitations, this study makes several important contributions. This is the first study to use nationally representative data to assess receipt of provider screening and advice for cessation across different tobacco products and across subgroups of adults coping with chronic conditions. The results reveal that while providers typically address cigarette smoking with their patients, there is considerable room for improvement in communication regarding the use of non-cigarette tobacco products. Healthcare provider (e.g., nurse, medical assistant, physician, dentist) training to expand screening and cessation interventions to include the growing spectrum of tobacco products should be a priority. There is also room for improvement in communication regarding treatment options for smokers, as less than one-third of smokers trying to quit use counseling or medication, ${ }^{34}$ even though such treatments can approximately double or triple the odds of success. ${ }^{35},{ }^{36}$ Our data also suggest that high rates of tobacco use among those coping with mental health and substance use disorders are not being adequately addressed by healthcare providers, which risks widening the already unsettling disparities in smokingrelated morbidity and mortality.
Corresponding Author: Diana R. Keith, PhD; Vermont Center on Behavior and Health, Department of Psychiatry, University of Vermont, 1 South Prospect St. Rm 1415, Burlington, VT 05403, USA (e-mail: Diana.Keith@uvm.edu).

\section{Compliance with Ethical Standards:}

Funding: This project was supported in part by Centers of Biomedical Research Excellence award P2OGM103644 from the National Institute of General Medical Sciences, and Institutional Training Award T32DA07242 from the National Institute on Drug Abuse. The funding sources had no role in this project other than financial support.

Conflict of Interest: The authors declare that they do not have a conflict of interest.

\section{REFERENCES}

1. Holford TR, Meza R, Warner KE, et al. Tobacco control and the reduction in smoking-related premature deaths in the United States, 1964-2012. JAMA. 2014;311(2):164-171.

2. Warner KE, Sexton DW, Gillespie BW, et al. Impact of tobacco control on adult per capita cigarette consumption in the United States. Am J Public Health. 2014; 104(1):83-89.

3. Centers for Disease Control and Prevention. Current Cigarette Smoking Among Adults-United States, 2005-2014. Morb Mortal Wkly Rep. 2015;64(44):1233-1240.

4. Higgins ST, Kurti AN, Redner R, et al. A literature review on prevalence of gender differences and intersections with other vulnerabilities to tobacco use in the United States, 2004-2014. Prev Med. 2015;80:89-100.

5. Higgins ST, Kurti AN, Redner $\mathbf{R}$, et al. Co-occurring risk factors for current cigarette smoking in a U.S. nationally representative sample. Prev Med. 2016

6. Jamal A, Homa DM, O'Connor E, et al. Current cigarette smoking among adults - United States, 2005-2014. MMWR Morb Mortal Wkly Rep. 2015;64(44): 1233-1240.

7. Kasza KA, Ambrose BK, Conway KP, et al. Tobacco-Product Use by Adults and Youths in the United States in 2013 and 2014. N Engl J Med. 2017;376(4):342-353.

8. Stanton CA, Keith DR, Gaalema DE, et al. Trends in tobacco use among US adults with chronic health conditions: National Survey on Drug Use and Health 2005-2013. Prev Med. 2016

9. Danesh D, Paskett ED, Ferketich AK. Disparities in receipt of advice to quit smoking from health care providers: 2010 National Health Interview Survey. Prev Chronic Dis. 2014;11:E131.

10. Fiore MC, Jaen CR. A clinical blueprint to accelerate the elimination of tobacco use. JAMA. 2008;299(17):2083-2085.

11. Nicholson JM, Hennrikus DJ, Lando HA, et al. Patient recall versus physician documentation in report of smoking cessation counselling performed in the inpatient setting. Tob Control. 2000;9(4):382-388.

12. Thorndike AN, Rigotti NA, Stafford RS, et al. National patterns in the treatment of smokers by physicians. JAMA. 1998;279(8):604-608.

13. Lucan SC, Katz DL. Factors associated with smoking cessation counseling at clinical encounters: the Behavioral Risk Factor Surveillance System (BRFSS) 2000. Am J Health Promot. 2006;21(1):16-23.

14. Ossip-Klein DJ, McIntosh S, Utman C, et al. Smokers ages 50+: who gets physician advice to quit? Prev Med. 2000;31(4):364-369.

15. Spangler JG, Song EY, Pockey JR, et al. Predictors of Clinician Tobacco Intervention Counseling in Six North Carolina Free Clinics. Tob Use Insights. 2012;20125:11-16.

16. Tomar SL, Husten CG, Manley Mw. Do dentists and physicians advise tobacco users to quit? J Am Dent Assoc. 1996;127(2):259-265.

17. Substance Abuse and Mental Health Services Administration (SAMSHA). Results from the 2013 National Survey on Drug Use and Health: Summary of National Findings. NSDUH Series H-46 (HHS Publication No (SMA) 14-4863). Rockville, MD; 2014.

18. Substance Abuse and Mental Health Services Administration (SAMSHA) 2014 National Survey on Drug Use and Health: Methodological Summary and Definitions. Cent Behav Health Stat Qual. 2015.

19. Goodman RA, Posner SF, Huang ES, et al. Defining and measuring chronic conditions: imperatives for research, policy, program, and practice. Prev Chronic Dis. 2013;10:E66. 
20. American Psychological Association. Diagnostic and Statistical Manual of Mental Disorders. Washington, DC; 2000.

21. Kruger J, Shaw L, Kahende J, et al. Health care providers' advice to quit smoking, National Health Interview Survey, 2000, 2005, and 2010. Prev Chronic Dis. 2012;9:E130.

22. Weaver KE, Danhauer SC, Tooze JA, et al. Smoking cessation counseling beliefs and behaviors of outpatient oncology providers. Oncologist. 2012;17(3):455-462.

23. Schauer GL, Wheaton AG, Malarcher AM, et al. Health-care Provider Screening and Advice for Smoking Cessation Among Smokers With and Without COPD: 2009-2010 National Adult Tobacco Survey. Chest. 2016;149(3):676-684.

24. Fiore MC, Jaen CR, Baker TB, et al. A Clinical Practice Guideline for Treating Tobacco Use and Dependence: 2008 Update - A US Public Health Service report. Am J Prev Med. 2008;35(2):158-176.

25. US Department of Health and Human Services. The health consequences of smoking - 50 years of progress. A report of the Surgeon General. US Dept of Health and Human Services, Centers for Disease Control and Prevention, National Center for Chronic Disease Prevention and Health Promotion, Office on Smoking and Health. 2014

26. McMillen RC, Gottlieb MA, Shaefer RM, et al. Trends in Electronic Cigarette Use Among U.S. Adults: Use is Increasing in Both Smokers and Nonsmokers. Nicotine Tob Res. 2015;17(10):1195-1202.

27. US Department of Health and Human Services. E-Cigarette Use Among Youth and Young Adults. A Report of the Surgeon General. U.S. Department of Health and Human Services, Centers for Disease Control and Prevention, National Center for Chronic Disease Prevention and Health Promotion, Office on Smoking and Health. Atlanta, GA; 2016.
28. Virtanen SE, Zeebari Z, Rohyo I, et al. Evaluation of a brief counseling for tobacco cessation in dental clinics among Swedish smokers and snus users. A cluster randomized controlled trial (the FRITT study). Prev Med. 2015;70:26-32.

29. Callaghan RC, Veldhuizen S, Jeysingh T, et al. Patterns of tobaccorelated mortality among individuals diagnosed with schizophrenia, bipolar disorder, or depression. J Psychiatr Res. 2014;48(1): 102-110.

30. Druss BG, Zhao L, Von Esenwein S, et al. Understanding excess mortality in persons with mental illness: 17-year follow up of a nationally representative US survey. Med Care. 2011;49(6):599-604.

31. Centers for Disease Control and Prevention. Vital Signs: Current Cigarette Smoking Among Adults Aged $\geq 18$ Years With Mental Illness-United States, 2009-2011. Morb Mortal Wkly Rep. 2013;62 (05):81-87.

32. Centers for Disease Control and Prevention. Vital Signs Fact Sheet: Adult Smoking Focusing on People with Mental Illness, February 2013. National Center for Chronic Disease and Health Promotion, Office on Smoking and Health. 2013.

33. Banham L, Gilbody S. Smoking cessation in severe mental illness: what works? Addiction. 2010;105(7):1176-1189.

34. Centers for Disease Control and Prevention. Quitting smoking among adults-United States, 2001-2010. MMWR Morb Mortal Wkly Rep. 2011;60(44):1513-1519.

35. Kotz D, Brown J, West R. 'Real-world' effectiveness of smoking cessation treatments: a population study. Addiction. 2014;109(3):491-499.

36. Silagy CL, Stead L, Mant D, Fowler G. Nicotine replacement therapy for smoking cessation. Cochrane Database Syst Rev. 2004;3(Art. No.: CD000146). 